\title{
SYPL1 overexpression predicts poor prognosis of hepatocellular carcinoma and associates with epithelial-mesenchymal transition
}

\author{
DONG-HAN CHEN ${ }^{1}$, QIU-WAN WU ${ }^{2}$, XIU-DONG LI ${ }^{3}$, SHUANG-JIA WANG ${ }^{3 *}$ and ZHI-MING ZHANG ${ }^{2 *}$ \\ ${ }^{1}$ Department of General Surgery, Second Xiangya Hospital, Central South University, Changsha, Hunan 410011; \\ ${ }^{2}$ Biobank, The First Affiliated Hospital of Xiamen University, Teaching Hospital of Fujian Medical University, \\ Xiamen, Fujian 361003; ${ }^{3}$ Department of Hepato-Biliary-Pancreatic and Vascular Surgery, \\ The First Affiliated Hospital of Xiamen University, Xiamen, Fujian 361003, P.R. China
}

Received January 14, 2017; Accepted June 7, 2017

DOI: 10.3892/or.2017.5843

\begin{abstract}
Hepatocellular carcinoma (HCC) is the second leading cause of cancer mortality worldwide, which is mainly due to relapse and metastasis. Synaptophysin-like 1 (SYPL1), a member of SYP family proteins, exerts complicated functions, which prompted us to wonder whether SYPL1 contributed to HCC progress. Herein, we performed integrative experiments of quantitative real-time polymerase chain reaction (qRT-PCR), western blot analysis and immunohistochemistry (IHC), and found that SYPL1 overexpression in HCC tissues was closely correlated with several malignant clinicopathologic features of HCC. The results from IHC in serial sections of HCC tissues further indicated that SYPL1 expression was associated with epithelial-mesenchymal transition (EMT) biomarkers of HCC cells. Additionally, Kaplan-Meier survival analysis showed that SYPL1 overexpression was significantly associated with reduced overall survival $(\mathrm{OS})(\mathrm{P}<0.001)$ and disease-free survival (DFS) $(\mathrm{P}=0.002)$. Furthermore, univariate and multivariate Cox proportional hazards analysis identified SYPL1 as an independent prognostic factor for OS [hazard ratio (HR), $2.443,95 \%$ confidence interval (CI), 1.429-4.177, $\mathrm{P}=0.001$ ] and DFS (HR, 1.680, 95\% CI=1.012-2.788, $\mathrm{P}=0.045)$ of $\mathrm{HCC}$ patients. Collectively, SYPL1 overexpression predicts poor
\end{abstract}

Correspondence to: Dr Shuang-Jia Wang, Department of HepatoBiliary-Pancreatic and Vascular Surgery, The First Affiliated Hospital of Xiamen University, Xiamen, Fujian 361003, P.R. China E-mail: abian-03@163.com

Dr Zhi-Ming Zhang, Biobank, The First Affiliated Hospital of Xiamen University, Teaching Hospital of Fujian Medical University, 55 Zhenhai Road, Xiamen, Fujian 361003, P.R. China

E-mail: zhangzhiming164@xmu.edu.cn

*Contributed equally

Abbreviations: AFP, alpha-fetoprotein; HBsAg, hepatitis B surface antigen; TNM, tumor node metastasis; BCLC, Barcelona Clinic Liver Cancer

Key words: hepatocellular carcinoma, Synaptophysin-like 1, prognosis, metastasis, epithelial-mesenchymal transition prognosis of HCC and may associate with EMT of HCC cells. Therefore, SYPL1 could serve as a future novel biomarker and potential therapy target for HCC.

\section{Introduction}

Hepatocellular carcinoma (HCC) is the second leading cause of cancer mortality worldwide. In 2012, there were approximately 782,500 new cases and 745,500 deaths of HCC globally, with more than half of both occurring in China (1). Although liver resection or transplantation provides the best chances of long-term survival for selected patients with early stage HCC, almost all HCC patients diagnosed at advanced stage are always deprived of surgery, resulting in even poorer prognosis with a 5 -year survival rate of $5.1 \%(2,3)$. The reasons are ascribed to relapse and metastasis, which remain hard to conquer (4). Complex signaling inside and outside cancer cells orchestrate the considerably varied metastatic potential (5), leading to invalid staging systems for predicting prognosis of HCC (6). Currently only limited drugs have been proved to have some effect on HCC patients, and even the best characterized and unique FDA-approved, Sorafenib efficacy for unresectable HCC, is often disappointing (7). Therefore, more useful tumor biomarkers to identify HCC patients at high risk for poor survival and subsequently to render precise adjuvant therapies need to be established urgently.

Synaptophysin-like 1 (SYPL1), encoded by the SYPL1 gene, belongs to the SYP family proteins (8). Although originally reported as a protein related to the neuroendocrine specific synaptophysin, SYPL1 has recently been identified in nonneuronal tissues, and its mRNA was significantly abundant in adipose tissues and accordingly increased during adipogenesis of 3T3-L1 cells (9). SYPL1 exerts transporter activity and is a broadly distributed membrane component of small cytoplasmic transport vesicles associated with GLUT4-containing vesicles in adipocytes (10) and also extracellular exosome (11). Recently, SYPL1 was also reported as a probable regulator of NF- $\kappa \mathrm{B}$ signaling pathway, though its exact functional role remains unknown (12). Although a previous study demonstrated that SYPL1 staining was restricted to cells surrounding sinusoids in liver, and undetectable in hepatocytes (9), upregulation of SYPL1 has been observed according to the 
data from high-resolution, array-based comparative genomic hybridization and transcriptome analysis of HCC samples (13). Collectively, the expression pattern and known functional role of SYPL1 prompted us to wonder whether and how SYPL1 contributed to HCC progress.

In the present study, quantitative real-time polymerase chain reaction (qRT-PCR), western blot analysis (WB) and immunohistochemical (IHC) staining were performed revealing that SYPL1 was upregulated in HCC tissues when compared with the matched adjacent non-tumor liver tissues (ANLTs) from the same patients. In addition, the ectopic SYPL1 expression in HCC was further demonstrated to be correlated with multiple malignant clinicopathological features and was identified as an independent prognostic factor for the OS and DFS of HCC patients. Mechanistically, SYPL1 might be associated with epithelial-mesenchymal transition (EMT) of HCC cells via $\mathrm{NF}-\kappa \mathrm{B} /$ Snail signaling.

\section{Materials and methods}

Ethics. The present study conformed to the ethical guidelines of the World Medical Association Declaration of HelsinkiEthical Principles for Medical Research Involving Human Subjects and was approved by the Institutional Research Board at the First Affiliated Hospital of Xiamen University, China. Written informed consent was obtained from each patient. Institutional Ethics Committee approval for this project was provided before the commencement of the study. All specimens were handled according to the ethical and legal standards.

Patients and tissue specimens. Specimens, including HCC tissues and the matched adjacent non-tumor liver tissues (ANLTs) which were collected from areas $>2 \mathrm{~cm}$ away from the tumor edge, were from $122 \mathrm{HCC}$ patients receiving curative hepatectomy at the Department of Hepato-Biliary-Pancreatic and Vascular Surgery of the First Affiliated Hospital of Xiamen University from January 2005 to December 2010 (Fig. 1). None of the patients had received preoperative chemotherapy or radiotherapy. Each specimen was divided into two parts; one was snap-frozen in liquid nitrogen and stored at $-80^{\circ} \mathrm{C}$ for later RNA extraction, the other was formalin-fixed and paraffin embedded for IHC. Among these specimens, 30 and 16 of fresh HCC tissues and the matched ANLTs were randomly selected for qRT-PCR and WB, respectively. The clinicopathological data including age, sex, tumor size, alpha-fetoprotein (AFP) level, nodal status, histological grade, microvascular invasion (MVI) and TNM, were collected from patient files. These patients included $101(82.8 \%)$ males and 21 (17.2\%) females, with a median age of 43 years (range, 21-79 years). The detailed clinical features of the 122 patients are presented in Table I. Histopathology was evaluated by two certified pathologists, and staged according to the criteria of the seventh edition of the American Joint Committee on Cancer/International Union against Cancer TNM classification system.

Quantitative real-time reverse-transcription polymerase chain reaction $(q R T-P C R)$. Total RNA of fresh specimens were extracted from frozen materials by TRIzol reagent according to the manufacturer's protocol (Invitrogen, Carlsbad, CA, USA).
170 cases of randomly selected liver tumors from hepatectomy between Jan 2005 and Dec 2010 from the First Affiliated Hospital of Xiamen University were enrolled

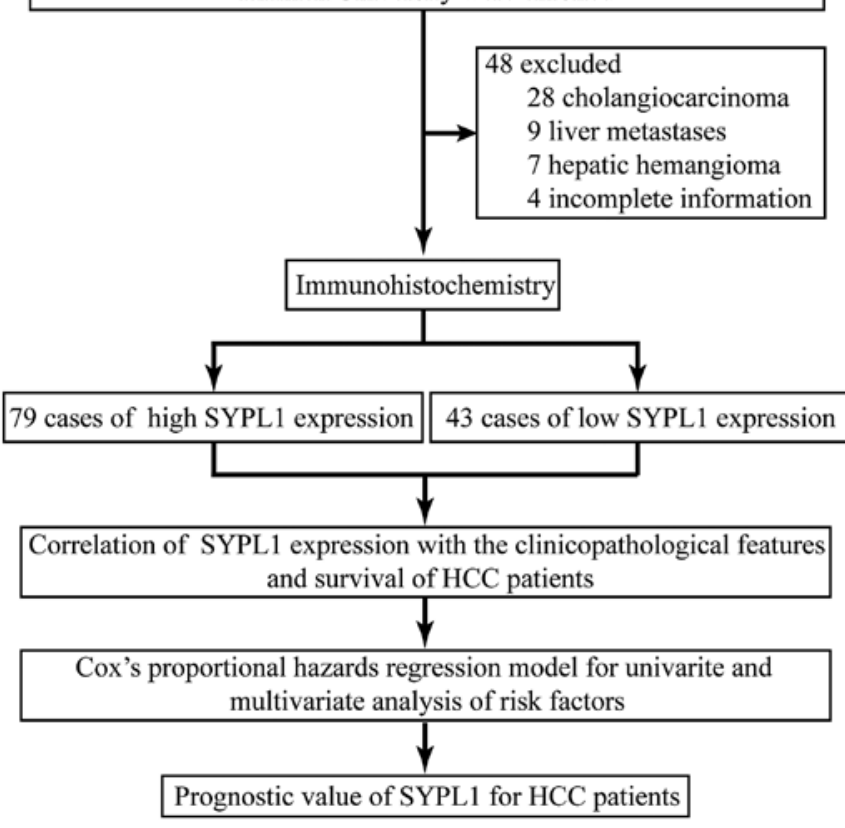

Figure 1. Flow chart of HCC patients enrolled in the present study.

Reverse transcription of total RNA into complementary DNA was conducted using the Takara reverse transcription reagents (Takara Bio, Inc., Shiga, Japan) at $37^{\circ} \mathrm{C}$ for $15 \mathrm{~min}$ followed by $85^{\circ} \mathrm{C}$ for $5 \mathrm{sec}$. Primers were designed using Primer Premier 5.0 software (Premier Biosoft, Waterloo, ON, Canada) and synthesized by Invitrogen. The primers of SYPL1 were as follows: forward, 5'-TATGTTGGCTACA CGAGTCTGT-3' and reverse, 5'-ACAAGGCGGAAGTTCA TCAATAA-3'; ACTB was used as a control with the following primers: forward, 5'-ACTCGTCATACTCCTGCT-3' and reverse, 5'-GAAACTACCTTCAACTCC-3'. The fold-change of SYPL1 mRNA expression in HCC tissues compared to adjacent nontumorous tissues was analyzed using $2^{-\Delta \Delta C t}$ method (14).

Western blot analysis. Total protein of fresh HCC specimens were extracted and quantified by BCA protein assay kit (Thermo Fisher Scientific, Waltham, MA, USA) for protein concentrations. Then, proteins were separated on $10 \%$ sodium dodecyl sulfate polyacrylamide gel electrophoresis (SDS-PAGE) and then transferred onto polyvinylidene fluoride membranes (Millipore). After blocking with 5\% skimmed milk in Trisbuffered saline containing $0.05 \%$ Tween-20, the membranes were incubated with a rabbit anti-SYPL1 monoclonal antibody (ab184176, 1:1,000 dilution; Abcam, Cambridge, MA, USA) overnight, followed by 20 -min incubation with horseradish peroxidase-conjugated secondary antibody. $\beta$-actin protein determined by a mouse anti- $\beta$-actin monoclonal antibody (ab8226, 1:4,000 dilution; Abcam) was used as a loading control. The band density was measured by ImageJ software, which was repeated three times (15).

Immunohistochemical staining. IHC was performed to further determine the expression pattern of SYPL1 in HCC tissues. 
Table I. The correlations of SYPL1 with clinicopathological features of $\mathrm{HCC}$.

\begin{tabular}{|c|c|c|c|c|}
\hline \multirow[b]{2}{*}{$\begin{array}{l}\text { Clinicopathological } \\
\text { variables }\end{array}$} & \multirow[b]{2}{*}{$\mathrm{n}$} & \multicolumn{2}{|c|}{ SYPL1 } & \multirow[b]{2}{*}{$\mathrm{P}$-value } \\
\hline & & $\begin{array}{c}\text { Low } \\
\text { expression }\end{array}$ & $\begin{array}{c}\text { High } \\
\text { expression }\end{array}$ & \\
\hline Sex & & & & 0.840 \\
\hline Female & 21 & 7 & 14 & \\
\hline Male & 101 & 36 & 65 & \\
\hline Age (years) & & & & 0.953 \\
\hline$\leq 60$ & 94 & 33 & 61 & \\
\hline$>60$ & 28 & 10 & 18 & \\
\hline $\operatorname{AFP}(\mathrm{ng} / \mathrm{ml})$ & & & & 0.458 \\
\hline$<20$ & 32 & 13 & 19 & \\
\hline$\geq 20$ & 90 & 30 & 60 & \\
\hline HBsAg & & & & 0.119 \\
\hline Negative & 20 & 4 & 16 & \\
\hline Positive & 102 & 39 & 63 & \\
\hline Liver cirrhosis & & & & 0.109 \\
\hline Absence & 32 & 15 & 17 & \\
\hline Presence & 90 & 28 & 62 & \\
\hline Tumor size $(\mathrm{cm})$ & & & & 0.049 \\
\hline$\leq 5$ & 48 & 22 & 26 & \\
\hline$>5$ & 74 & 21 & 53 & \\
\hline Tumor nodule no. & & & & 0.002 \\
\hline Solitary & 65 & 31 & 34 & \\
\hline Multiple ( $\geq 2$ ) & 57 & 12 & 45 & \\
\hline Capsular formation & & & & 0.029 \\
\hline Presence & 66 & 29 & 37 & \\
\hline Absence & 56 & 14 & 42 & \\
\hline $\begin{array}{l}\text { Edmondson-Steiner } \\
\text { grade }\end{array}$ & & & & 0.048 \\
\hline $\mathrm{I}+\mathrm{II}$ & 59 & 26 & 33 & \\
\hline III + IV & 63 & 17 & 46 & \\
\hline Microvascular invasion & & & & 0.002 \\
\hline Absence & 62 & 30 & 32 & \\
\hline Presence & 60 & 13 & 47 & \\
\hline TNM & & & & 0.032 \\
\hline Early (I + II) & 91 & 37 & 54 & \\
\hline Late (III + IV) & 31 & 6 & 25 & \\
\hline BCLC staging & & & & 0.026 \\
\hline $0+\mathrm{A}$ & 41 & 20 & 21 & \\
\hline$B+C$ & 81 & 23 & 58 & \\
\hline Liver function & & & & 0.778 \\
\hline Child-Pugh A & 73 & 25 & 48 & \\
\hline Child-Pugh B & 49 & 18 & 31 & \\
\hline
\end{tabular}

AFP, alpha-fetoprotein; HBsAg, hepatitis B surface antigen; TNM, tumor node metastasis; BCLC, Barcelona Clinic Liver Cancer.

The tissue specimens were fixed in $10 \%$ formalin and then embedded in paraffin; $4 \mathrm{~mm}$ sections were incised and placed on silane-coated slides. The V-9000 Polymer Detection System, DAB and hematoxylin (Beijing Zhongshan Golden Bridge Biotechnology, Co., Ltd., Beijing, China) were used for IHC staining according to the manufacturer's recommendations. Some specimens were stained with H\&E to confirm the diagnosis. Other sections of representative blocks were deparaffinized and dehydrated using gradient solvents. Following antigen retrieval in $0.01 \mathrm{M}$ sodium citrate buffer $(\mathrm{pH}$ 6.0) for $15 \mathrm{~min}$ at $95^{\circ} \mathrm{C}$, endogenous peroxidase was blocked with $3 \%$ $\mathrm{H}_{2} \mathrm{O}_{2}$. Ten percent of goat serum was used as blocking liquid for $15 \mathrm{~min}$. Thereafter, slides were incubated overnight at $4^{\circ} \mathrm{C}$ respectively with a rabbit anti-SYPL1 monoclonal antibody (ab184176, 1:250 dilution; Abcam), a mouse anti-vimentin monoclonal antibody (ZM-0260, 1:200 dilution; Beijing Zhongshan Golden Bridge Biotechnology) and a mouse antiE-cadherin monoclonal antibody (ZM-0092, 1:300 dilution; (Beijing Zhongshan Golden Bridge Biotechnology), a rabbit anti-NF-кB p65 polyclonal antibody (ab86299, 1:200 dilution; Abcam), a rabbit anti-Snail polyclonal antibody (ab85936, 1:200 dilution; Abcam). Further incubation was carried out with a secondary antibody followed by counterstaining with $\mathrm{DAB}$ and hematoxylin, and then ethanol dehydration was conducted by grade followed by addition of xylene to make the sections transparent. Finally, mounting was performed with neutral balsam. The staining intensity of proteins was evaluated on a four-step scale ( 0 , no staining; $1+$, weak intensity; $2+$, moderate intensity; and $3+$, strongest intensity). The staining fraction was scored according to the following criteria: 0 , no positive cancer cells; $1,<25 \%$ positive cancer cells; $2,26-50 \%$ positive cancer cells; and 3, >50\% positive cancer cells. Both staining intensity and fraction determined the overall staining score (16). Negative control slides were treated with the same original but non-immunologic serum followed by the secondary antibody under the same conditions. Two pathologists simultaneously evaluated immunostaining on a multihead microscope (Olympus BX43; Olympus, Tokyo, Japan).

Patient follow-up and prognostic study. The follow-up period was defined as an interval between the date of operation and the date patient died or the last follow-up, from January 2005 to December 2015. The follow-up of all surviving patients were performed periodically, including serum AFP levels, liver computed tomography (CT), ultrasonography and chest radiography every 1-2 months. For those highly suspected of relapsing or metastatic patients, other available diagnostic modalities such as hepatic angiography, magnetic resonance imaging (MRI), high-resolution chest CT and positron emission tomography (PET) were also comprehensively applied. We censored survival at 5 years after the initial resection surgery. Patients who died from other causes were defined as censored cases. The OS was defined as the interval between surgery and death regardless of etiology, and the DFS was defined as the interval between surgery and tumor relapse or metastasis.

Statistical analysis. All data were analyzed using the SPSS statistical software, version 18.0, for Windows (SPSS, Inc., Chicago, IL, USA). The correlation between SYPL1 expression and clinicopathological parameters was evaluated using the Pearson $\chi^{2}$ test. Survival curves were constructed 

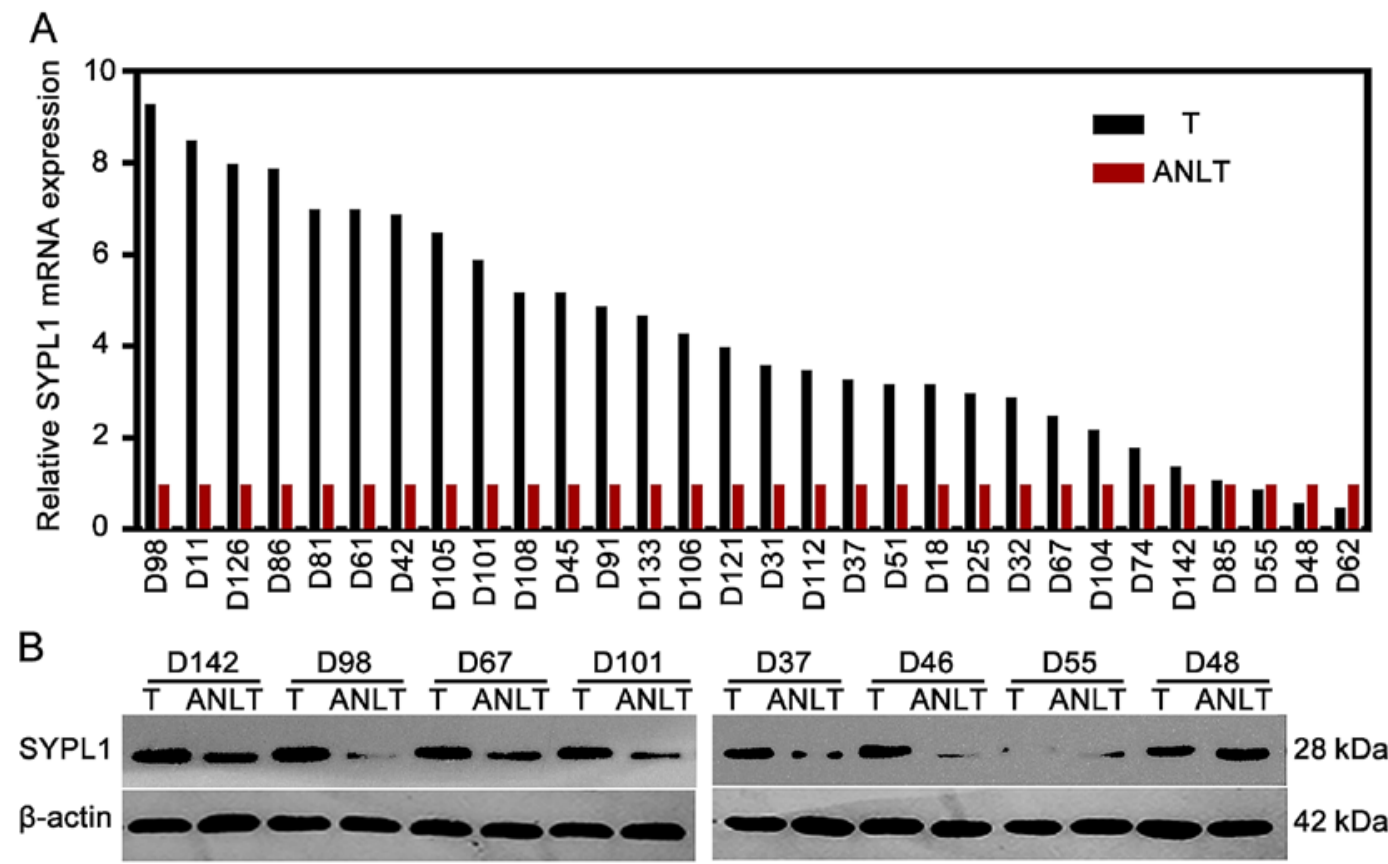

C

HCC
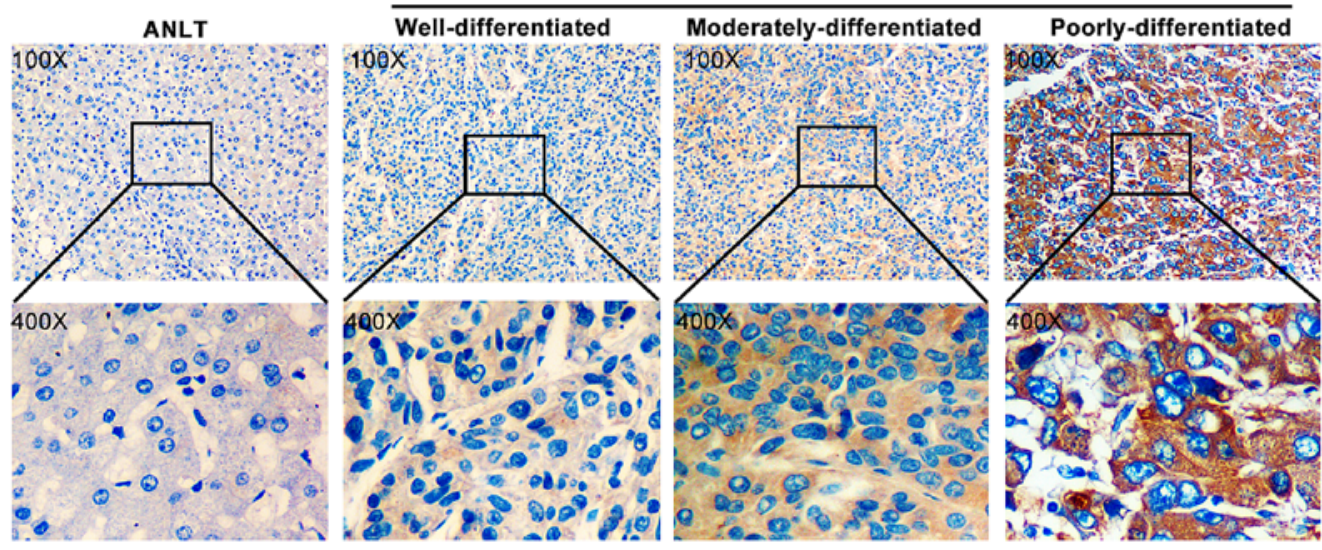

Figure 2. SYPL1 expression is upregulated in human HCC tissues as analyzed by (A) quantitative real-time PCR (mean $\pm \mathrm{SD}, 3.69 \pm 0.45$ vs. $0.88 \pm 0.17$; $\mathrm{P}<0.001$ ); (B) western blot analysis. (C) Representative IHC images of SYPL1 expression in HCC and ANLT. T, HCC tissue; ANLT, adjacent non-tumor liver tissue.

by the Kaplan-Meier method and evaluated by the log-rank test. The independent risk factors associated with the overall and disease-free survival of HCC patients were identified by establishing the Cox proportional hazards regression model. A two-tailed $\mathrm{P}<0.05$ was considered statistically significant.

\section{Results}

SYPL1 is significantly overexpressed in HCC tissues. The results from qRT-PCR showed that the relative SYPL1 mRNA expression level in HCC tissues was obviously higher than that in the matched ANLT tissues (mean $\pm \mathrm{SD}, 3.69 \pm 0.45$ vs. $0.88 \pm 0.17$; $\mathrm{P}<0.001$ ) (Fig. 2A). Consistently, the western blot results showed that the expression of SYPL1 protein in HCC tissues was also significantly higher than that in the matched ANLT tissues ( $\mathrm{P}=0.026)$ (Fig. 2B). To further determine the relationship between the expression pattern of SYPL1 and the clinical significance in HCC patients, IHC staining was performed and showed SYPL1 was broadly and significantly upregulated in HCC tissues, compared with the matched ANLT tissues
$(\mathrm{P}<0.001)$ (Fig. 2C). The subcellular location of SYPL1 was mainly in the cytoplasm, plasma membrane and extracellularly located. Based on the SYPL1 staining in HCC tissues, these patients were divided into two groups: low (IHC level 0-1) vs. high (IHC level 2-3)-SYPL1 expression groups, respectively. Of the 122 HCC specimens, 79 (64.8\%) manifested significantly high expression level of SYPL1 protein, while 43 (35.2\%) expressed relatively low level of the protein. Moreover, significantly higher expression level of SYPL1 was observed in the poorly differentiated HCC tissues than that in well or moderately differentiated HCC $(\mathrm{P}=0.048)($ Fig. 2C).

Elevated SYPL1 expression is associated with malignant clinicopathological features and predicts poor prognosis of HCC patients. Then we evaluated the relationship between SYPL1 expression and clinicopathological features of HCC patients. Of note, the expression level of SYPL1 was significantly associated with tumor size, tumor nodule number, capsular formation, Edmondson-Steiner grade, MVI, Barcelona Clinic Liver Cancer (BCLC) stage and tumor node metastasis 

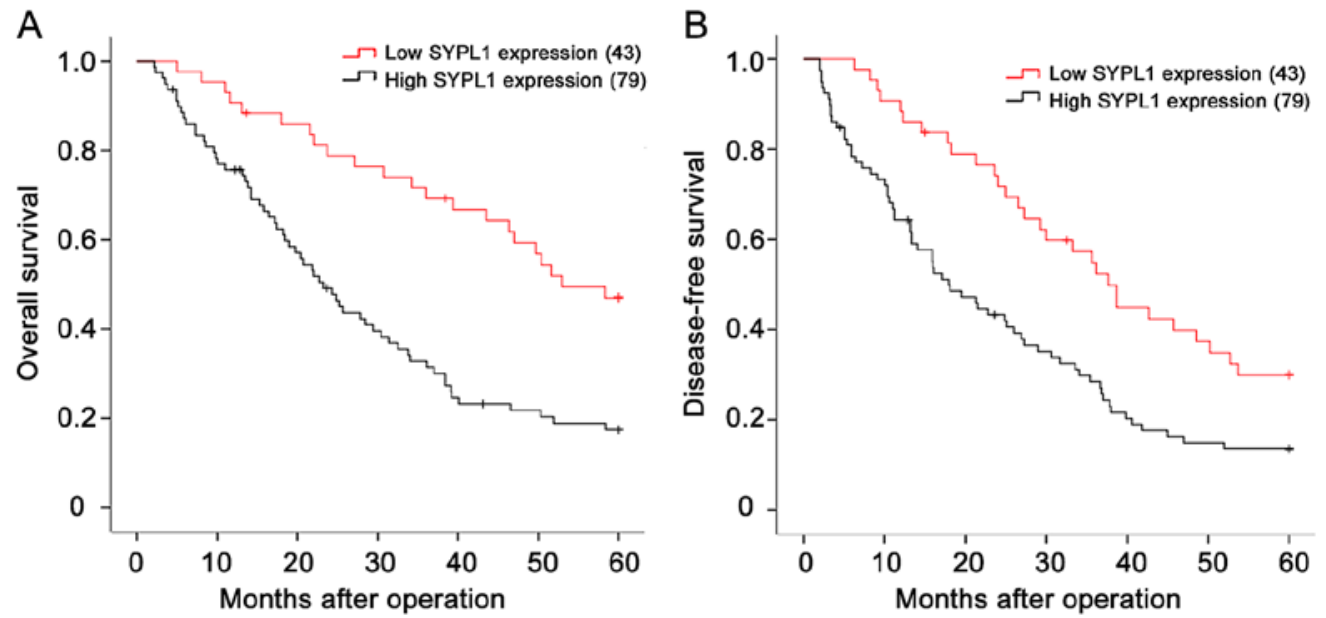

Figure 3. SYPL1 overexpression predicts poor prognosis. (A) The overall survival (OS) and (B) disease-free survival (DFS) of HCC patients with high or low SYPL1 expression. Survival curve was calculated with the log-rank test.

A

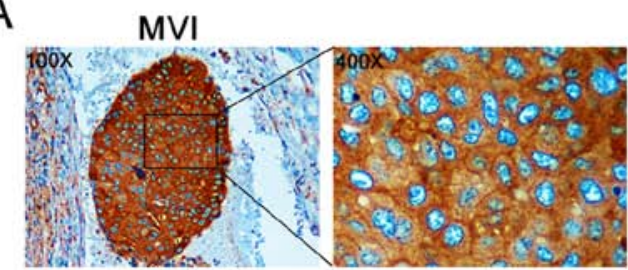

C

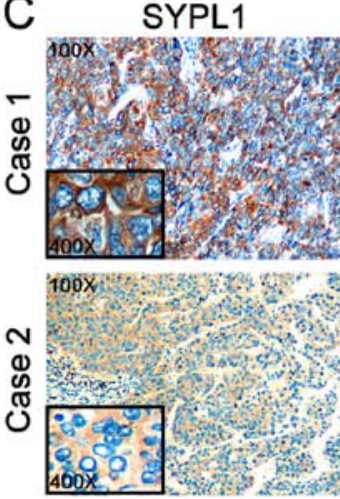

NF-кB

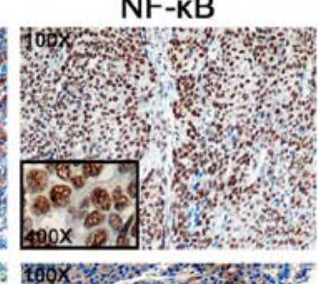

$\underline{B}$

\begin{tabular}{|c|c|c|c|c|}
\hline & \multicolumn{2}{|c|}{ SYPL1 } & \multirow{2}{*}{$\begin{array}{l}P \\
r\end{array}$} \\
\hline & & Low expression & High expression & \\
\hline & Absence & 30 & 32 & 0.004 \\
\hline & Presence & 13 & 47 & 0.257 \\
\hline
\end{tabular}

Snail

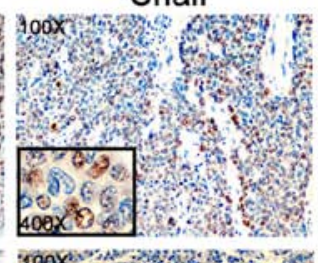

E-Cadherin
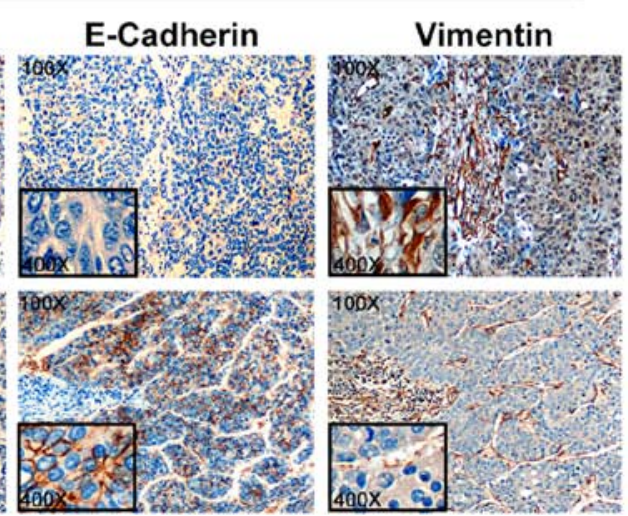

Figure 4. SYPL1 expression is associated with presence of MVI and EMT of HCC cells. (A) Representative IHC images of SYPL1 expression with MVI. (B) The correlation between SYPL1 expression and presence of MVI was analyzed by the Spearman's rank correlation test. (C) Representative IHC images of SYPL1, NF-кB, Snail, E-cadherin and vimentin expression in consecutive tissue sections of HCC.

(TNM) stage (all $\mathrm{P}<0.05$; Table I). HCC patients with high SYPL1 expression in the tumor specimens had reduced OS (1-, 3- and 5-year OS: 74.7, 30.4 and 15.2 vs. 90.7, 67.4 and 44.2\%; P<0.001) and DFS (1-, 3- and 5-year DFS: 70.9, 26.6 and 12.7 vs. $88.4,62.8$ and $27.9 \%$; $\mathrm{P}=0.002)$ than those with relatively low SYPL1 expression (Fig. 3A and B). Furthermore, univariate and multivariate analysis indicated that high SYPL1 expression was an independent risk factor for both OS and DFS of HCC patients after liver resection (Tables II and III). These results adequately revealed that SYPL1 was closely associated with malignant clinicopathological features, and could serve as a novel independent prognosis biomarker for $\mathrm{HCC}$ patients after hepatic resection.

Elevated SYPL1 expression is associated with the presence of MVI and EMT of HCC cells. Among the aforementioned malignant clinicopathological features that closely associated with SYPL1 expression, the presence of MVI interested us greatly, because the HCC cells in MVI displayed significant ectopic SYPL1 expression (Fig. 4A). The significance of MVI is drawing increasing attention, not only from clinicians but also researchers, to predict the prognosis of HCC patients. Moreover, MVI has been recognized as a better predictor of tumor recurrence and OS rate following surgical resection compared to the Milan Criteria. Therefore, we analyzed the MVI in specimens obtained from HCC patients with liver resection, and the prevalence of MVI was $49.2 \%$ (60 in 122). Astonishingly, the presence of MVI was much more frequently present in the high-SYPL1 expression group than in the low-SYPL1 expression group (59.5 vs. 30.2\%, $\mathrm{P}=0.002$ ) (Table I). Furthermore, Spearman test was performed and showed that ectopic SYPL1 was significantly correlated 
Table II. Univariate and multivariate analysis of factors associated with overall survival.

\begin{tabular}{|c|c|c|c|c|c|}
\hline \multirow[b]{2}{*}{ Variables } & \multirow[b]{2}{*}{$\mathrm{n}$} & \multicolumn{2}{|c|}{ Univariate analysis } & \multicolumn{2}{|c|}{ Multivariate analysis } \\
\hline & & RR $(95 \% \mathrm{CI})$ & P-value & $\mathrm{RR}(95 \% \mathrm{CI})$ & P-value \\
\hline \multicolumn{6}{|l|}{ Sex } \\
\hline Female & 21 & 1 & & & \\
\hline Male & 101 & $1.122(0.632-1.992)$ & 0.694 & n.a. & n.a. \\
\hline \multicolumn{6}{|l|}{ Age (years) } \\
\hline$\leq 60$ & 94 & 1 & & & \\
\hline$>60$ & 28 & $1.455(0.887-2.385)$ & 0.138 & n.a. & n.a. \\
\hline \multicolumn{6}{|l|}{$\operatorname{AFP}(\mathrm{ng} / \mathrm{ml})$} \\
\hline$<20$ & 32 & 1 & & & \\
\hline$\geq 20$ & 90 & $0.999(0.618-1.614)$ & 0.997 & n.a. & n.a. \\
\hline \multicolumn{6}{|l|}{ HBsAg } \\
\hline Negative & 20 & 1 & & & \\
\hline Positive & 102 & $0.957(0.529-1.729)$ & 0.884 & n.a. & n.a. \\
\hline \multicolumn{6}{|l|}{ Liver cirrhosis } \\
\hline Absence & 32 & 1 & & & \\
\hline Presence & 90 & $1.920(1.137-3.243)$ & 0.015 & n.a & n.a \\
\hline \multicolumn{6}{|l|}{ Tumor size (cm) } \\
\hline$\leq 5$ & 48 & 1 & & & \\
\hline$>5$ & 74 & $2.074(1.301-3.305)$ & 0.002 & n.a. & n.a. \\
\hline \multicolumn{6}{|c|}{ Tumor nodule number } \\
\hline Solitary & 65 & 1 & & & \\
\hline Multiple ( $\geq 2)$ & 57 & $1.645(1.065-2.542)$ & 0.025 & $\mathrm{n} . \mathrm{a}$ & $\mathrm{n} . \mathrm{a}$ \\
\hline \multicolumn{6}{|c|}{ Capsular formation } \\
\hline Presence & 66 & 1 & & & \\
\hline Absence & 56 & $1.666(1.083-2.563)$ & 0.020 & n.a & n.a \\
\hline \multicolumn{6}{|c|}{ Edmondson-Steiner grade } \\
\hline I-II & 59 & 1 & & & \\
\hline III-IV & 63 & $1.568(1.015-2.425)$ & 0.043 & n.a. & n.a. \\
\hline \multicolumn{6}{|c|}{ Microvascular invasion } \\
\hline Absence & 62 & 1 & & 1 & \\
\hline Presence & 60 & $2.455(1.573-3.831)$ & 0.002 & n.a & $\mathrm{n} . \mathrm{a}$ \\
\hline \multicolumn{6}{|l|}{ TNM } \\
\hline Early (I-II) & 91 & 1 & & & \\
\hline Late (III-IV) & 31 & $3.194(2.011-5.072)$ & $<0.001$ & $2.479(1.480-4.151)$ & 0.001 \\
\hline \multicolumn{6}{|l|}{ BCLC staging } \\
\hline $0-\mathrm{A}$ & 41 & 1 & & 1 & \\
\hline$B+C$ & 81 & $2.192(1.353-3.551)$ & 0.001 & $1.760(1.013-3.059)$ & 0.045 \\
\hline \multicolumn{6}{|l|}{ Liver function } \\
\hline Child-Pugh A & 73 & 1 & & & \\
\hline Child-Pugh B & 49 & $1.512(0.980-2.332)$ & 0.062 & n.a. & n.a. \\
\hline \multicolumn{6}{|c|}{ SYPL1 expression } \\
\hline Low & 43 & 1 & & 1 & \\
\hline High & 79 & $2.637(1.612-4.314)$ & $<0.001$ & $2.443(1.429-4.177)$ & 0.001 \\
\hline
\end{tabular}

with the presence of MVI (rho=0.257, $\mathrm{P}=0.004)$, (Fig. 4B). Therefore, these results indicated that ectopic SYPL1 expression might be involved in HCC cells invading to microvessels.
During the metastatic cascade, tumor cells acquire enhanced ability to infiltrate into blood stream, and some settle to proliferate and form MVI. EMT, a critical mechanism 
Table III. Univariate and multivariate analysis of factors associated with disease-free furvival.

\begin{tabular}{|c|c|c|c|c|c|}
\hline \multirow[b]{2}{*}{ Variables } & \multirow[b]{2}{*}{$\mathrm{n}$} & \multicolumn{2}{|c|}{ Univariate analysis } & \multicolumn{2}{|c|}{ Multivariate analysis } \\
\hline & & $\mathrm{RR}(95 \% \mathrm{CI})$ & P-value & $\mathrm{RR}(95 \% \mathrm{CI})$ & P-value \\
\hline \multicolumn{6}{|l|}{ Sex } \\
\hline Female & 21 & 1 & & & \\
\hline Male & 101 & $1.200(0.690-2.085)$ & 0.518 & n.a. & n.a. \\
\hline \multicolumn{6}{|l|}{ Age (years) } \\
\hline$\leq 60$ & 94 & 1 & & & \\
\hline$>60$ & 28 & $1.398(0.879-2.221)$ & 0.157 & n.a. & n.a. \\
\hline \multicolumn{6}{|l|}{$\mathrm{AFP}(\mathrm{ng} / \mathrm{ml})$} \\
\hline$<20$ & 32 & 1 & & & \\
\hline$\geq 20$ & 90 & $1.074(0.680-1.697)$ & 0.758 & n.a. & n.a. \\
\hline \multicolumn{6}{|l|}{ HBsAg } \\
\hline Negative & 20 & 1 & & & \\
\hline Positive & 102 & $0.978(0.563-1.698)$ & 0.936 & n.a. & n.a. \\
\hline \multicolumn{6}{|l|}{ Liver cirrhosis } \\
\hline Absence & 32 & 1 & & & \\
\hline Presence & 90 & $1.944(1.192-3.172)$ & 0.008 & $\mathrm{n} . \mathrm{a}$ & n.a \\
\hline \multicolumn{6}{|l|}{ Tumor size (cm) } \\
\hline$\leq 5$ & 48 & 1 & & 1 & \\
\hline$>5$ & 74 & $2.267(1.458-3.523)$ & $<0.001$ & $1.705(1.019-2.853)$ & 0.042 \\
\hline \multicolumn{6}{|c|}{ Tumor nodule number } \\
\hline Solitary & 65 & 1 & & & \\
\hline Multiple ( $\geq 2$ ) & 57 & $1.525(1.014-2.293)$ & 0.043 & n.a & n.a \\
\hline \multicolumn{6}{|c|}{ Capsular formation } \\
\hline Presence & 66 & 1 & & & \\
\hline Absence & 56 & $1.859(1.233-2.802)$ & 0.003 & n.a & n.a \\
\hline \multicolumn{6}{|c|}{ Edmondson-Steiner grade } \\
\hline I-II & 59 & 1 & & & \\
\hline III-IV & 63 & $1.560(1.035-2.350)$ & 0.034 & n.a. & n.a. \\
\hline \multicolumn{6}{|c|}{ Microvascular invasion } \\
\hline Absence & 62 & 1 & & & \\
\hline Presence & 60 & $2.454(1.614-3.734)$ & 0.001 & n.a & n.a \\
\hline \multicolumn{6}{|l|}{ TNM } \\
\hline Early (I-II) & 91 & 1 & & 1 & \\
\hline Late (III-IV) & 31 & $2.998(1.903-4.722)$ & $<0.001$ & $2.306(1.385-3.841)$ & 0.001 \\
\hline \multicolumn{6}{|l|}{ BCLC staging } \\
\hline $0-\mathrm{A}$ & 41 & 1 & & 1 & \\
\hline $\mathrm{B}+\mathrm{C}$ & 81 & $2.495(1.579-3.942)$ & $<0.001$ & $1.962(1.163-3.309)$ & 0.012 \\
\hline \multicolumn{6}{|l|}{ Liver function } \\
\hline Child-Pugh A & 73 & 1 & & & \\
\hline Child-Pugh B & 49 & $1.739(1.148-2.633)$ & 0.009 & n.a. & n.a. \\
\hline \multicolumn{6}{|c|}{ SYPL1 expression } \\
\hline Low & 43 & 1 & & 1 & \\
\hline High & 79 & $2.006(1.292-3.113)$ & 0.002 & $1.680(1.012-2.788)$ & 0.045 \\
\hline
\end{tabular}

which endowed motility to tumor cells, was associated with formation of MVI (17). As mentioned above, we had found ectopic SYPL1 was significantly correlated with the presence of MVI, therefore, we tried to determine the correlation between the expression pattern of SYPL1 and EMT markers, E-cadherin and vimentin. Notably, HCC tissues which had 
elevated expression of SYPL1 protein were also detected high level of vimentin, accompanying with little or even no E-cadherin expression; and vice versa (Fig. 4C). These results indicated that ectopic SYPL1 expression was associated with EMT of HCC cells, which might facilitate MVI formation, and the underlying mechanism of which is still worthy of further interpretation.

Elevated SYPL1 expression is associated with EMT of HCC cells, which might be mediated via $\mathrm{NF- \kappa B/Snail} \mathrm{signaling}$ pathway. We then tried to gain insight into the mechanism, which linked SYPL1 expression and the EMT of HCC cells. In a recent study screening for regulators of the NF- $\mathrm{\kappa B}$ signaling pathways via performing a genome-wide siRNA, SYPL1 was identified as a potential regulator of NF- $\mathrm{KB}$ (12). Since the critical role of NF- $\mathrm{KB} /$ Snail signaling in HCC progress, especially the significant role on EMT-inducing (18), we inquired into whether SYPL1 associated with NF- $\mathrm{kB} /$ Snail signaling and EMT of HCC cells. IHC staining was performed to further determine the co-expression patterns of SYPL1, NF-кB, Snail, E-cadherin and vimentin in $\mathrm{HCC}$ tissues. These staining results from serial section showed an obviously positive expression of SYPL1, NF- $\kappa$ B, Snail and vimentin, whereas there was notably negative expression of E-cadherin (Fig. 4C). These results suggest that SYPL1 might be involved in NF- $\mathrm{KB} /$ Snail signaling pathway, via which SYPL1 facilitated EMT of HCC cells and even MVI formation.

\section{Discussion}

In the present study, we demonstrated that the ectopic expression of SYPL1 in HCC tissues predicted poor prognosis of HCC patients with reduced OS and DFS rates. Mechanistically, SYPL1 might be involved in NF- $\mathrm{kB} /$ Snail signaling pathway and associate with EMT of HCC cells, which may lead to an enhanced mobility of HCC cells to invade into vascular system to form MVI, resulting in relapse and metastasis (19). To the best of our knowledge, these observations are the first evidence supporting the role of SYPL1 in tumor progress. In previous studies, SYPL1 was reported to be involved with cellular exosomes (11), which are considered as critical factors of HCC progress (20). Moreover, as a phosphoprotein component of adipocyte transport vesicles, SYPL1 associated with GLUT4containing vesicles (10), while GLUT-4 was associated with the development of several diseases, including tumor progress and EMT (21). In addition, SYPL1 was suggested to be a potential regulator of NF- $\mathrm{KB}$ (12). NF- $\mathrm{BB}$ signaling is a wellknown and critical regulator contributing to tumorigenesis and progress. The above indicated that SYPL1 might play a critical role in cancer.

EMT, recognized as a central process in the complex metastatic cascade of HCC, can dissociate collective HCC cells and endow them more motile and invasive properties (22), facilitate their invading through the basement membrane into the vascular system and then surviving or proliferating, followed by extravasating out of the circulation system at distant organ sites to settle and constitute premetastatic niches, ultimately forming macroscopic metastases $(5,23)$. The hallmarks of EMT include disruption of EMT-related transcript factors, such as Snail, TWIST and ZEB; and loss of epithelial adherent junctions, concomitant with a development of a migratory phenotype (24). These changes are characterized as downregulation of epithelial markers of E-cadherin and upregulation of mesenchymal markers, such as $\mathrm{N}$-cadherin, vimentin and fibronectin. In the present study, we found an obviously positive correlation among SYPL1, NF- $\mathrm{BB}$, Snail and vimentin expression, whereas a negative correlation of E-cadherin expression in HCC tissues with the four proteins mentioned above. These results suggested that SYPL1 might associate with EMT of $\mathrm{HCC}$ cells via NF- $\mathrm{BB} /$ Snail signaling pathway.

MVI, defined as a microscopic evidence of cancer cell clusters existing in vessels of the tumor capsule and/or in surrounding liver parenchyma (25), has been included in the AJCC staging system (26). As a histopathologic feature, the presence of MVI is a verified indicator for aggressive behavior of HCC, and is directly related to early recurrence within 2 years after curative liver resection or/and even orthotopic liver transplantation $(27,28)$. According to previous reports, the prevalence of MVI in the specimens obtained from liver resection or transplantation of HCC patients was between 15.0 and $57.1 \%(29,30)$. However, in this study, the prevalence of MVI in the specimens obtained from liver resection of HCC patients was $49.2 \%$ generally, with a significantly higher prevalence in the high-SYPL1 expression group than that in the low-SYPL1 expression group (59.5 vs. 30.2\%, $\mathrm{P}=0.002$; Table I). There have been many efforts on preoperative estimation of MVI over the past decade. The 'typical dynamical pattern' (i.e., arterial enhancement and washout) on contrast-enhanced magnetic resonance imaging (MRI) was reported to be closely associated with MVI (31), even though other investigators questioned the potential interobserver variability before further prospective validation for these results to avoid it (29). More recently, a preoperative prediction model was developed, in which variables associated with MVI in patients who underwent resection of $\mathrm{HCC}$ were used, with a secondary aim to confirm the importance of MVI on long-term outcomes (32). Moreover, a research group suggested Nomogram for preoperative estimation of MVI risk in Hepatitis B Virus-Related HCC, but they also recognized that Nomogram estimation, to some extent, might lack reliability and accuracy; therefore, they suggested that the combined usage of specific markers to estimate MVI might further improve the accuracy of Nomogram (19). Some experts have also proposed the use of serum or other biomarkers to estimate preoperative prediction of MVI risk for HCC patients (33). Disappointingly, these biomarkers failed to identify HCC patients with MVI from the patients with benign liver disease (34). In spite of this, we demonstrated a close correlation between ectopic SYPL1 expression and the presence of MVI in HCC patients with poor prognosis, which suggest SYPL1 might be a good tumor biomarker for preoperative MVI prediction to identify patients at high risk of relapse and metastasis.

This study has some limitations. Firstly, it was totally based on data from clinical tissues, without further verified in the HCC cell lines. More studies are needed to determine the function of SYPL1 by manipulating its expression level in $\mathrm{HCC}$ cells. Secondly, activation or inactivation of NF- $\mathrm{KB}$ as well as the translocation of NF- $\mathrm{kB}$ complexes, all of which 
would obviously influence the $\mathrm{NF}-\kappa \mathrm{B}$ signaling pathway, subsequently affect the expression level of downstream targeted genes through regulating chromatin structure (35). The correlation between SYPL1 and NF- $\kappa \mathrm{B} /$ Snail signaling we found here may be the complement of $N F-\kappa B$ signaling pathway, which require further functional tests to explore the underlying mechanism.

In conclusion, we provided the first evidence that SYPL1 overexpression is associated with the progress and the clinicopathological features of HCC mentioned above, especially the presence of MVI. Furthermore, mechanistically, ectopic SYPL1 expression might be associated with EMT of HCC cells via $\mathrm{NF}-\kappa \mathrm{B} /$ Snail signaling pathway. Therefore, SYPL1 may be a valuable biomarker for understanding metastatic mechanisms in individual patient; and hence, to be a potential target for tailoring treatment on an individual basis.

\section{Acknowledgements}

The present study was supported by grants from the National Natural Science Foundation of China (no. 81672595 to Z.-M.Z. and no. 81302287 to Q.-W.W.), the Youth Innovation Project of Fujian Province Natural Science Foundation (no. 2014D011 to S.-J.W.) and the Health Industry Joint Project of Fujian Provincial Natural Science Foundation (no. 2015J01554 to S.-J.W.).

\section{References}

1. Torre LA, Bray F, Siegel RL, Ferlay J, Lortet-Tieulent J and Jemal A: Global cancer statistics, 2012. CA Cancer J Clin 65: 87-108, 2015.

2. Llovet JM and Bruix J: Molecular targeted therapies in hepatocellular carcinoma. Hepatology 48: 1312-1327, 2008.

3. Njei B, Rotman Y, Ditah I and Lim JK: Emerging trends in hepatocellular carcinoma incidence and mortality. Hepatology 61: 191-199, 2015.

4. Ferrer-Fàbrega J, Forner A, Liccioni A, Miquel R, Molina V, Navasa M, Fondevila C, García-Valdecasas JC, Bruix J and Fuster J: Prospective validation of $a b$ initio liver transplantation in hepatocellular carcinoma upon detection of risk factors for recurrence after resection. Hepatology 63: 839-849, 2016.

5. Hanahan D and Weinberg RA: Hallmarks of cancer: The next generation. Cell 144: 646-674, 2011.

6. Roayaie S, Blume IN, Thung SN, Guido M, Fiel MI, Hiotis S, Labow DM, Llovet JM and Schwartz ME: A system of classifying microvascular invasion to predict outcome after resection in patients with hepatocellular carcinoma. Gastroenterology 137: $850-855,2009$.

7. NCCN Clinical Practice Guidelines in Oncology Hepatobiliary Cancers Version 2. 2015. http://www.nccn.org/professionals/ physician_gls/pdf/hepatobiliary.pdf

8. Andersen Ø, Johnsen H, De Rosa MC, Præbel K, Stjelja S, Kirubakaran TG, Pirolli D, Jentoft $S$ and Fevolden SE: Evolutionary history and adaptive significance of the polymorphic Pan I in migratory and stationary populations of Atlantic cod (Gadus morhua). Mar Genomics 22: 45-54, 2015.

9. Windoffer R, Borchert-Stuhlträger M, Haass NK, Thomas S, Hergt M, Bulitta CJ and Leube RE: Tissue expression of the vesicle protein pantophysin. Cell Tissue Res 296: 499-510, 1999.

10. Brooks CC, Scherer PE, Cleveland K, Whittemore JL, Lodish HF and Cheatham B: Pantophysin is a phosphoprotein component of adipocyte transport vesicles and associates with GLUT4containing vesicles. J Biol Chem 275: 2029-2036, 2000.

11. Prunotto M, Farina A, Lane L, Pernin A, Schifferli J, Hochstrasser DF, Lescuyer P and Moll S: Proteomic analysis of podocyte exosome-enriched fraction from normal human urine. J Proteomics 82: 193-229, 2013.
12. Warner N, Burberry A, Franchi L, Kim YG, McDonald C, Sartor MA and Núñez G: A genome-wide siRNA screen reveals positive and negative regulators of the NOD2 and NF- $\kappa \mathrm{B}$ signaling pathways. Sci Signal 6: rs3, 2013.

13. Roessler S, Long EL, Budhu A, Chen Y, Zhao X, Ji J, Walker R, Jia HL, Ye QH, Qin LX, et al: Integrative genomic identification of genes on $8 \mathrm{p}$ associated with hepatocellular carcinoma progression and patient survival. Gastroenterology 142: 957-966. e12, 2012.

14. Schmittgen TD and Livak KJ: Analyzing real-time PCR data by the comparative C(T) method. Nat Protoc 3: 1101-1108, 2008.

15. Carvajal-Vergara X, Sevilla A, D'Souza SL, Ang YS, Schaniel C, Lee DF, Yang L, Kaplan AD, Adler ED, Rozov R, et al: Patientspecific induced pluripotent stem-cell-derived models of LEOPARD syndrome. Nature 465: 808-812, 2010.

16. Wang Y,Bu F, Royer C, Serres S, Larkin JR, Soto MS, Sibson NR, Salter V, Fritzsche F, Turnquist C, et al: ASPP2 controls epithelial plasticity and inhibits metastasis through $\beta$-catenin-dependent regulation of ZEB1. Nat Cell Biol 16: 1092-1104, 2014.

17. Wang X, Ma C, Zong Z, Xiao Y, Li N, Guo C, Zhang L and Shi Y: A20 inhibits the motility of HCC cells induced by TNF- $\alpha$. Oncotarget 7: 14742-14754, 2016.

18. Qin Y, Zhao D, Zhou HG, Wang XH, Zhong WL, Chen S, Gu WG, Wang W, Zhang $\mathrm{CH}$, Liu YR, et al: Apigenin inhibits NF- $\kappa \mathrm{B}$ and snail signaling, EMT and metastasis in human hepatocellular carcinoma. Oncotarget 7: 41421-41431, 2016.

19. Lei Z, Li J, Wu D, Xia Y, Wang Q, Si A, Wang K, Wan X, Lau WY, Wu M, et al: Nomogram for preoperative estimation of microvascular invasion risk in hepatitis B virus-related hepatocellular carcinoma within the Milan criteria. JAMA Surg 151: 356-363, 2016.

20. Wei JX, Lv LH, Wan YL, Cao Y, Li GL, Lin HM, Zhou R, Shang CZ, Cao J, He H, et al: Vps4A functions as a tumor suppressor by regulating the secretion and uptake of exosomal microRNAs in human hepatoma cells. Hepatology 61: 1284-1294, 2015.

21. Li Q, Qin Y, Wei P, Lian P, Li Y, Xu Y, Li X, Li D and Cai S: Gas1 inhibits metastatic and metabolic phenotypes in colorectal carcinoma. Mol Cancer Res 14: 830-840, 2016.

22. Xiao S, Chang RM, Yang MY, Lei X, Liu X, Gao WB, Xiao JL and Yang LY: Actin-like 6A predicts poor prognosis of hepatocellular carcinoma and promotes metastasis and epithelial-mesenchymal transition. Hepatology 63: 1256-1271, 2016.

23. Nieto MA: Epithelial plasticity: A common theme in embryonic and cancer cells. Science 342: 1234850, 2013.

24. Valastyan S and Weinberg RA: Tumor metastasis: Molecular insights and evolving paradigms. Cell 147: 275-292, 2011.

25. Shirabe K, Toshima T, Kimura K, Yamashita Y, Ikeda T, Ikegami T, Yoshizumi T, Abe K, Aishima S and Maehara Y: New scoring system for prediction of microvascular invasion in patients with hepatocellular carcinoma. Liver Int 34: 937-941, 2014.

26. Sobin LH and Compton CC: TNM seventh edition: what's new, what's changed: communication from the International Union Against Cancer and the American Joint Committee on Cancer. Cancer 116: 5336-5339, 2010.

27. Roayaie S, Frischer JS, Emre SH, Fishbein TM, Sheiner PA, Sung M, Miller CM and Schwartz ME: Long-term results with multimodal adjuvant therapy and liver transplantation for the treatment of hepatocellular carcinomas larger than 5 centimeters. Ann Surg 235: 533-539, 2002.

28. Yao FY, Ferrell L, Bass NM, Bacchetti P, Ascher NL and Roberts JP: Liver transplantation for hepatocellular carcinoma: Comparison of the proposed UCSF criteria with the Milan criteria and the Pittsburgh modified TNM criteria. Liver Transpl 8: 765-774, 2002.

29. Rodríguez-Perálvarez M, Luong TV, Andreana L, Meyer T, Dhillon AP and Burroughs AK: A systematic review of microvascular invasion in hepatocellular carcinoma: Diagnostic and prognostic variability. Ann Surg Oncol 20: 325-339, 2013.

30. Portolani N, Coniglio A, Ghidoni S, Giovanelli M, Benetti A, Tiberio GA and Giulini SM: Early and late recurrence after liver resection for hepatocellular carcinoma: Prognostic and therapeutic implications. Ann Surg 243: 229-235, 2006.

31. Kim MJ, Lee M, Choi JY and Park YN: Imaging features of small hepatocellular carcinomas with microvascular invasion on gadoxetic acid-enhanced MR imaging. Eur J Radiol 81: 2507-2512, 2012 . 
32. Schlichtemeier SM, Pang TC, Williams NE, Gill AJ, Smith RC, Samra JS, Lam VW, Hollands M, Richardson AJ, Pleass HC, et al: A pre-operative clinical model to predict microvascular invasion and long-term outcome after resection of hepatocellular cancer: The Australian experience. Eur J Surg Oncol 42: 1576-1583, 2016.

33. Gouw AS, Balabaud C, Kusano H, Todo S, Ichida T and Kojiro M: Markers for microvascular invasion in hepatocellular carcinoma: Where do we stand? Liver Transpl 17 (Suppl 2): S72-S80, 2011.
34. Sterling RK, Wright EC, Morgan TR, Seeff LB, Hoefs JC, Di Bisceglie AM, Dienstag JL and Lok AS: Frequency of elevated hepatocellular carcinoma (HCC) biomarkers in patients with advanced hepatitis C. Am J Gastroenterol 107: 64-74, 2012. 35. Chen LF and Greene WC: Shaping the nuclear action of NF-kappaB. Nat Rev Mol Cell Biol 5: 392-401, 2004. 